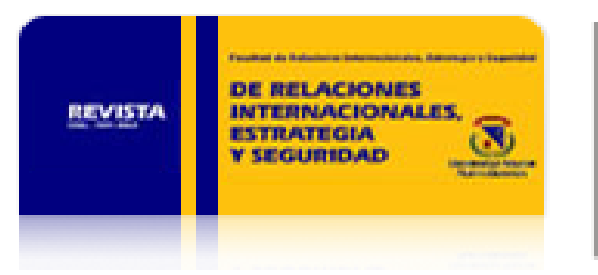

Revista de Relaciones Internacionales, Estrategia y Seguridad

ISSN: 1909-3063

cinuv.relinternal@unimilitar.edu.co

Universidad Militar Nueva Granada

Colombia

García Neumann, Jaime

¿ESTADOS FALLIDOS O ESTADOS EN CRISIS?

Revista de Relaciones Internacionales, Estrategia y Seguridad, vol. 4, núm. 1, enero-junio, 2009, pp.

201-207

Universidad Militar Nueva Granada

Bogotá, Colombia

Disponible en: http://www.redalyc.org/articulo.oa?id=92712970012

- Cómo citar el artículo

- Número completo

- Más información del artículo

Página de la revista en redalyc.org

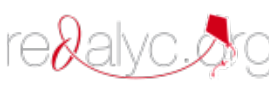

Sistema de Información Científica

Red de Revistas Científicas de América Latina, el Caribe, España y Portugal

Proyecto académico sin fines de lucro, desarrollado bajo la iniciativa de acceso abierto 


\section{¿ESTADOS FALLIDOS O ESTADOS EN CRISIS?}

Jaime García Neumann*

La proliferación de los Ilamados 'Estados fallidos' (failed States) se ha convertido en una característica de la era post-globalización en todo el mundo, y tiende a agravarse en los próximos tiempos, cuando golpeen con mayor fuerza los efectos devastadores de la crisis económica iniciada en 2008 con la ruptura de la burbuja financiera global. ¿Qué hacer? ¿Cuál es la tipología de estos procesos de descomposición de los Estados nacionales? ¿Qué peligro representan para su propia población o para la comunidad internacional? ¿Cuáles son sus causas? ¿Pueden prevenirse? ¿Cómo pueden recuperarse? ¿Cuáles son los efectos y límites de la 'intervención militar humanitaria'? ¿Qué criterios de política han seguido hasta ahora los demás Estados y los organismos internacionales ante estos hechos? ¿Qué nuevos enfoques se discuten en el ámbito del derecho, la ética, la seguridad y las relaciones internacionales?

Para todo el que quiera conocer el 'estado del arte' sobre este problema, que sobrepasa por su importancia y extensión el in-

*Licenciado en Filosofía, USB, Bogotá

Máster en Planificación del Desarrollo, UCV, Caracas

Doctor en Filosofía del Derecho, U. de Valencia. PDA 
terés de sólo los especialistas, puede ser de gran utilidad la lectura de ¿Estados fallidos o Estados en crisis?, publicado recientemente por la editorial Comares y escrito por la investigadora de la Universidad de Valencia, Encarnación Fernández.

Primero, porque describe de manera general el amplio panorama conceptual y político normativo que se ha ido desplegando alrededor de la desestructuración de los Estados nacionales, desde los Estados 'frágiles' en sus instituciones políticas hasta aquellos que finalmente colapsan como tales, dando lugar a dinámicas catastróficas de violencia y destrucción para su propia población o partes de ella, generando a su vez un problema para los Estados vecinos y un peligro para la comunidad internacional. Se incluye además en este panorama la comparación del problema de los Estados desestructurados o fallidos en diferentes momentos históricos, desde la reconstrucción de postguerra y la descolonización africana, hasta el final de la Guerra Fría, cuando se comienzan a multiplicar los casos de descomposición de los Estados, llegando al período actual donde el problema ha llegado a ser prioritario en la geopolítica de las grandes potencias, tras los atentados del 11-S, la situación de guerra al terrorismo global y la definición de 'Estados delincuentes' (rogue States) o 'fuera de la ley' (outlaw States).

Pero, en segundo lugar, porque este libro va más allá. Se trata de una indagación valiente, realizada con inteligencia y sensibilidad, lo cual no es muy frecuente. La autora no teme hacerse las preguntas más difíciles acerca de las causas internas y externas por las que los países pobres llegan a ser considerados 'Estados fallidos'; también, sobre el estatuto ético y jurídico de las intervenciones internacionales y sobre la eficacia de las mismas. No tiene inconveniente en situarse más allá de unas y otras ideologías, para indagar en la realidad de los Estados descompuestos y cuestionar lo políticamente correcto y las verdades aparentes establecidas en el ámbito académico e institucional del mundo desarrollado, acerca del peligro para la seguridad internacional que representan los 'Estados fallidos', el derecho a intervenir más que el deber de prevenir, y el globalismo político en lugar del papel insustituible de los Estados nacionales en garantizar la seguridad humana de sus ciudadanos.

Deja muchas preguntas abiertas, es verdad, pero de eso precisamente trata el libro: de desenmarañar la compleja red de procesos e intereses económicos, políticos y militares públicos y privados que subyacen en la descomposición de los Estados en crisis, en su catalogación como 'fallidos' y en su manejo de crisis en el ámbito de las relaciones internacionales globalizadas. Y lo hace, no tanto para presentar alternativas acabadas y definitivas, salvo en aspectos específicos, sino para reabrir y reorientar el debate, de manera que es el lector quien debe sacar sus propias conclusiones en medio de las diversas posiciones analizadas y confrontadas. Por ello el título del libro es también una pregunta abierta que sugiere un cambio en la concepción y la formulación de políticas: ¿Se trata de Estados fallidos y fracasados? ¿O de Estados a cuya crisis ha contribuido en alguna forma determinante la dinámica globalizadora y cuya reconstitución interna es también responsabilidad de todos los implicados?

El libro consta de cuatro partes. En el primer capítulo, E. Fernández hace literalmente un barrido conceptual sobre lo que se considera un 'Estado fallido', así como el origen del término y la nume- 
rosa terminología clasificatoria utilizada por analistas, juristas, instituciones y organismos internacionales para designar distintos aspectos de los procesos de crisis y descomposición interna que padecen muchos Estados, así como los peligros que pueden representar para sus poblaciones y para la seguridad internacional. Para ello recorre los autores más diversos, desde Rawls a Duffield, pasando por Thürer, Tadjbakhsh, M.B. Taylor y S. Sur, entre otros.

Establece una diferencia fundamental entre los 'Estados fallidos' y los Ilamados Estados 'forajidos', 'delincuentes' o 'fuera de la ley'. En el primer caso, se trataría más que todo de Estados fragmentados que por distintas razones no pueden garantizar su seguridad interna y el monopolio legítimo de la fuerza, generándose procesos de violencia que pueden dañar gravemente los derechos humanos de su población y afectar las naciones vecinas. En el segundo caso, se trataría de Estados que pueden proteger o ser controlados por organizaciones criminales, el terrorismo internacional, el narcotráfico, los traficantes de arsenales de armas, convirtiéndose de este modo en un peligro inaceptable para la paz y la seguridad internacionales. La autora constata a continuación que la frontera entre unos y otros no siempre es clara y que suele confundirse en la práctica. Señala además que, desde el 11-S y la declaración de guerra al terrorismo internacional por parte de la primera potencia mundial y sus aliados, el énfasis ha cambiado de la discusión jurídica y política sobre las intervenciones en principio humanitarias para proteger los derechos humanos (Somalia, Haití, Bosnia, Kosovo), a la justificación de intervenir por motivos de seguridad internacional (Afganistán, Irak y, potencialmente, Corea del Norte o Irán).

Ya en la introducción, E. Fernández ha presentado una observación básica para la rigurosidad de su análisis: el principal riesgo de etiquetar los Estados en el espacio de las relaciones internacionales es el de servir de justificación para las intervenciones extranjeras por parte de Estados poderosos. En otras palabras, diríamos, la de establecer una doble regla en las relaciones internacionales, en la renuncia al uso de la fuerza, el respeto a la soberanía y la no intervención en los asuntos internos, tratándose de unos Estados u otros, lo cual vulnera los principios básicos del derecho internacional expresado, entre otros, en la Carta fundacional de la Organización de las Naciones Unidas.

Existen, sin embargo, situaciones de hecho en que Estados en crisis no pueden garantizar la seguridad de sus poblaciones y entran en una espiral negativa de fragmentación, bandos armados en pugna, contrabando de recursos y de armas, pillaje, refugiados internos, hambruna, violencia de todo tipo, donde la principal afectada es la población civil, con repercusiones graves en otras naciones. La comunidad internacional no puede volver a permanecer impasible, como ocurrió ante el genocidio de Ruanda mientras interviene en situaciones mucho menos graves o francamente dudosas. ¿Qué hacer entonces?

El libro se define por un criterio fundamental: la doctrina de la seguridad humana, propuesta originalmente en el Informe sobre Desarrollo Humano 1994 del PNUD. Como en otras ocasiones, la autora rescata el concepto general para depurarlo de malos usos y tergiversaciones. Al colocar como objetivo principal a los seres humanos más que la integridad territorial en sí o la seguridad 
del Estado, se produce un vuelco en la perspectiva de evaluar las situaciones críticas y en la manera de resolver los conflictos. En lugar de la amenaza y el uso de la fuerza, el énfasis estará en la persuasión y la negociación; en lugar de que la garantía interna de seguridad sea el poder de las armas, lo deben ser más bien las políticas de inclusión, la promoción del desarrollo y los derechos humanos; en lugar de utilizar primero el último recurso, como es la intervención militar directa, la prioridad estará en la prevención inteligente y, si ello no es posible, la ayuda para la reconstrucción y fortalecimiento de las instituciones del Estado, garante básico de toda seguridad, comenzando por la seguridad humana.

El segundo capítulo se refiere a las consecuencias internacionales de los Estados en crisis y las Ilamadas intervenciones humanitarias. A través de investigadores como S. Woodward, M. Aguirre, Ruiz-Giménez Arrieta, Ferrajoli y otros, se introduce en el debate ético y jurídico sobre la justificación o no de la intervención armada para evitar o poner fin a violaciones graves y masivas de los derechos humanos, así como su efectividad en casos concretos, particularmente en el período posterior al final de la Guerra Fría.

El libro retoma en este punto el principio de seguridad humana en el nuevo contexto del Informe sobre La responsabilidad de proteger, elaborado por la Comisión Internacional sobre Intervención y Soberanía de los Estados, organizada por Canadá, cuyos primeros resultados se presentaron en diciembre de 2001. No se le escapa a la autora la desconfianza y rechazo con que fue recibido el Informe por el Grupo de los 77 y otras agrupaciones internacionales que representan intereses de los países del Tercer Mundo en cuyo seno no se deja de considerar a Estados como Canadá, como la mano suave de la Commonwealth británica. Pero, de nuevo, busca rescatar el núcleo racional del desarrollo de los principios básicos de seguridad humana, intentando depurarlos de lo que denomina como 'contaminaciones' de otros intereses, incluyendo el nuevo curso estratégico surgido tras la declaración estadounidense de guerra al terrorismo global, que incorpora el problema de los Estados fallidos desde el punto de mira de la seguridad internacional.

Con esta perspectiva, distingue entre las acciones humanitarias y la eventual y extrema intervención directa, que de ningún modo puede calificarse como humanitaria; se busca prevenir la catástrofe para las poblaciones, más que actuar como reacción al desastre; fortalecer la función protectora del Estado afectado en lugar de socavar su soberanía. Sólo se podría recurrir a la intervención armada en casos extremos y excepcionales, y bajo determinadas condiciones. Pero, se pregunta, ¿qué es excepcional y cuál es la autoridad internacional para determinarlo, así como sus condiciones? El libro no elude las respuestas, en eventuales casos de hecho, de limpieza étnica y grandes pérdidas de vidas humanas, reales o inminentes, cumpliendo una serie de principios precautorios y bajo el mandato y supervisión de Naciones Unidas, siempre y cuando exista un fallo irreparable en la voluntad o capacidad del Estado en descomposición para proteger a la población en peligro.

Cuestiona, finalmente, algunos estereotipos establecidos, como que los Estados frágiles son de por sí una amenaza a la paz y la seguridad internacionales o que pueda aceptarse la noción de Estados 
fracasados. Más bien se establece la relación entre los Estados frágiles y su capacidad de gobernanza, así como la relación entre subdesarrollo y conflicto social, preguntándose por los prejuicios etnocéntricos occidentales para evaluar lo que deben ser los Estados y la herencia colonialista de considerar las diferencias como inferioridad. Puede concluirse a partir de estos principios que, más que Estados fallidos o fracasados, lo que existen son Estados en crisis, cuyas causas no son sólo internas sino, en buena medida, exógenas y globales.

El tercer capítulo se refiere a las causas del 'fracaso' de los Estados. En él, la autora lleva su indagación a señalar lo que pocas veces mencionan los informes internacionales en medio de la pugna ética y jurídica entre intervención internacional y soberanía nacional: la compleja interacción entre subdesarrollo y debilidad de los Estados, tras varias décadas de globalización económica y política. Citando a Alcalde Cardoza, indica el riesgo, por parte de los países avanzados, «de intentar frenar con una mano procesos de descomposición que estaría empujando con la otra» mediante la imposición de políticas económicas neoliberales.

E. Fernández presenta primero los argumentos de quienes atribuyen la creciente proliferación de Estados en descomposición a factores endógenos, como nuevas formas de barbarismo de grupos nacionalistas, étnicos y religiosos dentro de los Estados, que mantuvieron sus conflictos latentes durante la Guerra Fría y, una vez finalizada ésta, afloran con una violencia incontrolable (Huntington, Kaplan).

Basándose en las críticas de T. Pogge a Rawls y otros, presenta a continuación el denominado «nacionalismo explicativo», que atribuye las crisis terminales de numerosos Estados, especialmente los africanos, a su supuesta incapacidad crónica para gobernarse y establecer instituciones eficaces, por lo que no logran aprovechar las oportunidades que les brinda la economía globalizada. Algunos lo explican a partir de características políticas propias, como el clientelismo y el sistema de prebendas (Lookwood). Otros lo atribuyen a la mala gobernabilidad de las elites políticas locales, producto de la herencia colonial, cuyas características han mantenido a fin de perpetuarse en el poder (Akude).

Sin negar la incidencia de los factores locales, el libro hace un breve pero muy significativo recuento histórico de la interacción de procesos internos y externos, para explicar el creciente número de Estados fallidos no sólo en África sino en otros continentes. En este sentido menciona la pesada carga del colonialismo y el lento desarrollo hacia fuera y dominado por intereses estratégicos, durante el período poscolonial y de Guerra Fría, para detenerse en la intervención de las instituciones financieras internacionales (IFI) durante los años 70, la posterior crisis del endeudamiento externo, el Consenso de Washington, los planes de ajuste estructural impuestos por los organismos internacionales como el FMI y el Banco Mundial y, en general, las políticas neoliberales que han caracterizado la era de la globalización económica.

Se debe recordar, además, que las políticas globalizadoras de apertura de los mercados, desregulación y desprotección local, privatizaciones, devaluaciones y demás, pretendían expresamente la reducción 
del papel del Estado en la economía y, por consiguiente, en su capacidad para dirigir o impulsar el desarrollo y la protección social, generando una creciente debilidad del Estado y un aumento de la pobreza y las desigualdades en las naciones menos desarrolladas, que entraban a competir con desventaja en la ley de la selva del mercado libre global. A ello se suma, finalmente, "la maldición de los recursos naturales» que han atraído a los depredadores transnacionales a operar en estos países junto con bandas locales, agravando la inestabilidad política, la corrupción y la espiral de saqueo de recursos, comercio ilegal y violencia.

El último capítulo del libro se titula «Estados en crisis: ¿Qué hacer?». En él, E. Fernández aborda con mayor detalle las principales conclusiones que se han inferido de los debates anteriores, como la importancia de la prevención, los deberes de reconstrucción del Estado, el desafío de la pacificación y el desarrollo humano.

Para ello parte de una clara definición: entre el gobierno unimundial sin Estados nacionales (que vienen proponiendo los factores globalistas de poder y sus propagandistas académicos) y la reconstrucción de los Estados en crisis, la autora opta decididamente por la segunda alternativa, no sólo por ser más realista o «empírica» (S. Sur), sino por ser la única que puede garantizar la realización del principio guía de estas reflexiones, como es la seguridad humana de las poblaciones. Habría que añadir que la actual crisis financiera ha desacreditado la ilusión «maximalista» (S. Sur) de que el aumento de Estados fallidos es el anuncio cuasi-gnóstico del fin de los Estados nacionales y el comienzo de una 'nueva era' de gobierno unimundial (tipo 1984 de Orwell), propia de cierto progresismo cosmopolita. Ante la fracasada gobernanza global de facto de las grandes corporaciones privadas, sólo el Estado nacional puede ocuparse de la supervivencia y seguridad humanas de sus ciudadanos en medio de la crisis general.

El Estado -afirma E. Fernández- es la institución fundamental para garantizar los objetivos de la seguridad humana y los derechos humanos, por ello «lo que hay que superar no es el Estado sino el unilateralismo». De aquí se deriva que debe evitarse al máximo cualquier intervención externa de carácter coercitivo, sobre todo militar, ya que tiende a socavar o derrumbar la autoridad del Estado en crisis, y a agravar o extender los conflictos. Se requieren más bien iniciativas de la comunidad internacional y sus organismos para prevenir el colapso de los Estados o para su reconstrucción, según el caso, con la recuperación de sus instituciones, su legitimidad y su cohesión social.

Sobre la importancia de la prevención en la consolidación de la paz, el libro entra en detalles muy esclarecedores. Rescata, por ejemplo, los doce indicadores que utiliza el Fund for Peace para elaborar su extenso Índice de Estados Fallidos en el mundo (en 2007 y 2008 se analizan 177 países, en diversos grados, desde sostenibles a moderados, advertidos y fallidos), que publica anualmente Foreign Policy. Queda para el lector preguntarse sobre la autoridad e intereses de este think-tank estadounidense, pero los indicadores que utiliza bien pueden ser utilizados como 'alerta temprana' sobre los factores de crisis de los Estados, de manera que no hay excusas para no desarrollar políticas internacionales de prevención. 
Finalmente, en base a la experiencia acumulada de casos anteriores, se propone un amplio conjunto de tareas para la reconstrucción de los Estados, en particular los que han padecido graves conflictos internos, dejando de lado el sólo propósito inmediato de 'estabilizar' la situación y abandonar luego las ayudas internacionales, como suele suceder. El enfoque, de nuevo, debe ser integral y de mediano y largo plazo, comenzando por el paso de la violencia al monopolio legítimo de la fuerza por parte del Estado reconstituido, seguido por la llamada «justicia transicional» (comisiones de la verdad, justicia, perdón y reparación a las víctimas) con miras a una auténtica reconciliación nacional.

Por último, pero de importancia clave, la consolidación del Estado requiere nuevos programas de desarrollo económico en el sentido integral de desarrollo humano, que incluyan la seguridad alimentaria y la máxima participación de los factores urbanos y rurales en la reconstrucción socioeconómica del país, y donde el Estado deberá tener un papel impulsor y regulador. En todo caso, diferente a las fracasadas recetas neoliberales, ya que, como se indica al final del libro, citando a Woodward, hay un choque sustancial entre este modelo económico y la paz. 